\title{
The stress-strain state of the universal chassis of the tractor trailer in T-Flex
}

\author{
Ruslan Khakimzyanov ${ }^{*}$, Anvar Togaev ${ }^{1}$, and Aziz Rashidov ${ }^{1}$ \\ Tashkent State Transport University, Tashkent, Uzbekistan
}

\begin{abstract}
This article discusses the calculation of the strength of the frame structure of the universal chassis of the tractor trailer in the T-Flex software package and the comparative analysis of the results with experimental data and model data based on the principle of virtual work (possible movements).
\end{abstract}

\section{Introduction}

It is well known that the cultivation, collection, and storage of agricultural products is one of the most important tasks for all countries, including our republic. As demand for products grows, an important factor in achieving this goal is the production of inexpensive, efficient, and durable equipment used to grow, harvest, and transport it. One of the ways to solve this goal is to develop trailers with a universal chassis. Several large world companies JOCKIN (Belgium), ANNABURGER MultiLandPlus (Germany), Fliegl Agrartechnik (Germany), Cargo (Germany), and others, are engaged in the development and production of trailers with a universal chassis [1]. Similar tractor trailers are planned to be produced in Uzbekistan at the Tashkent Agricultural Machinery Plant.

Priyanka Ranu, Rajeev Singh Chauhan, Dr. V. N. Bartaria [3] used ANSYS to analyze the strength of the chassis frame with a force of $58860 \mathrm{~N}$. The calculations were performed for 3 different materials: steel, fiberglass, and carbon fiber. Analysis showed that carbon fiber material caused less deformation and stretching compared to fiberglass and steel material.

Divyesh N. Chaudhari, prof. Vinod M. Makwana, prof. Dharmeet J. Patel [4] focused on optimizing the chassis frame design, taking into account the movement of wheeled vehicles under dynamic, static, and cyclic loads. The chassis frame model was created by computer programs. Based on the analysis of the model, the weight and material of the structure were changed.

Mohd Azizi Muhammad Nor and others [5] carried out a comparative analysis of the data on the chassis load of a 35-ton trailer in the CATIA V5R18 software package and the data analytical calculations. The results showed good agreement between the values of the maximum torsions and some difference in magnitude.

The T-FLEX CAD computer complex is widely used in the CIS countries [6]. T-FLEX CAD is a computer-aided design system (CAD) with all modern tools for developing projects of any complexity. The program has powerful parametric 3D modeling capabilities

*Corresponding author: hakimotor@mail.ru 
and combines documentation and design tools. It is professional CAD software that combines the powerful parametric capabilities of $2 \mathrm{D}$ and $3 \mathrm{D}$ modeling with tools for creating and designing drawings and design documentation for a unified design documentation system.

To theoretically substantiate the frame of the universal chassis of the tractor trailer, which is the main element of the chassis, we use the algorithmic program T-Flex.

There are several advantages to using the T-Flex software. First, the operating system of the program is in Russian and is user-friendly. Secondly, its standard library is large, and the elements used to comply with the standards used in our country.

\section{Methods}

Let calculated the stress-strain state of the universal chassis of the tractor trailer in T-Flex $\mathrm{CAD}$ and received comparative analysis of the results.

The virtual model of the universal tractor trailer chassis in the T-Flex software package is shown in figure 1.

T-Flex CAD uses the finite element method for structural analysis. The finite element analysis program generates a system of equations, assumed initial and boundary conditions. The system of equations is solved to unknowns and is the values of characteristics within the elements. The principles of virtual movement are used to create equilibrium equations.

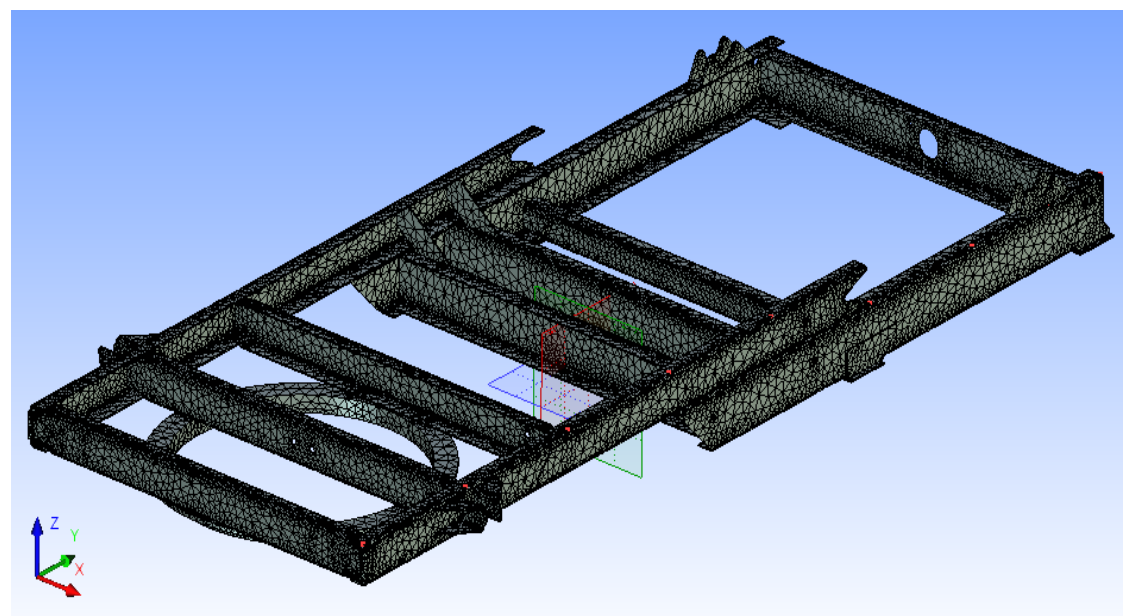

Fig. 1. Type of construction of the universal chassis of the tractor frame of the trailer with finite elements.

To perform computational work using the T-Flex CAD software package, the following values of the material used in the trailer frame, initial and boundary conditions were taken.

1. Simple carbon steel:

Elastic modulus: $2.1 \mathrm{E}+011 \mathrm{~N} / \mathrm{m} 2$

Poisson's ratio: 0.28

Shear modulus: $0 \mathrm{~N} / \mathrm{m} 2$

Thermal conductivity: $43 \mathrm{~W}(\mathrm{~m} \cdot \mathrm{K})$

Thermal expansion coefficient: 1.3E-005 1 / K

Mass density: $7800 \mathrm{~kg} / \mathrm{m} 3$

Yield strength: $2.2059 \mathrm{E}+008 \mathrm{~N} / \mathrm{m} 2$

Ultimate tensile strength: $3.99826 \mathrm{E}+008 \mathrm{~N} / \mathrm{m} 2$ 
Compressive strength: $3.99826 \mathrm{E}+008 \mathrm{~N} / \mathrm{m} 2$

Heat capacity: $440 \mathrm{~J}(\mathrm{~kg} \cdot \mathrm{K})$

2. Boundary conditions: Where the frame is connected to the springs, the rods are securely fixed on the turntable, the load $\mathrm{F}=66000 \mathrm{~N}$ acts on 4 points of the frame, the temperature is $\mathrm{T}_{0}=298 \mathrm{~K}\left(25^{\circ} \mathrm{C}\right)$.

3. Initial conditions: initial values of stress and displacement of frames are equal to zero.

Dividing the model into finite elements in the form of a tetrahedron.

\section{Results and Discussion}

Figure 2 shows the stress-strain state after designing the universal chassis frame of a tractor trailer under a load of $66,000 \mathrm{~N}$.

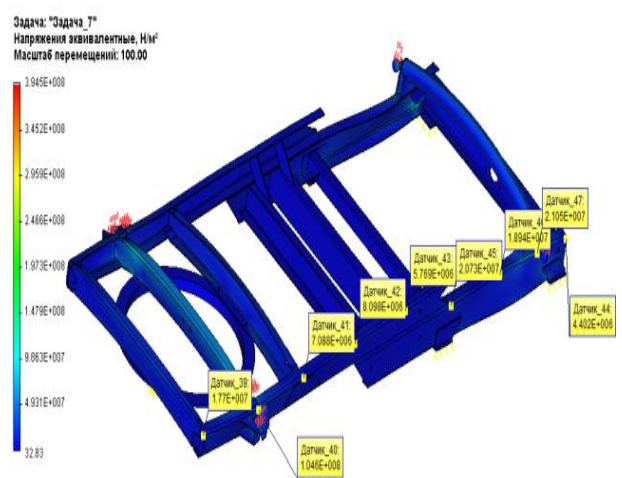

a)

3адаva: "כадауа 7 "

K- т запаса по эквивалентным напряжениям

Масштаб перемещений: 100.00 3арая: "Јадана 7 "

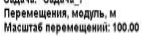

0

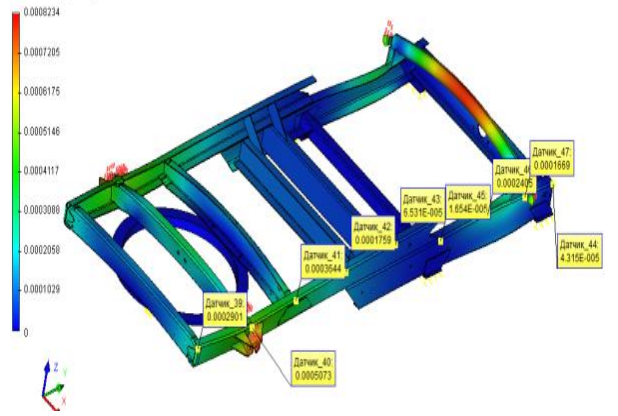

b)

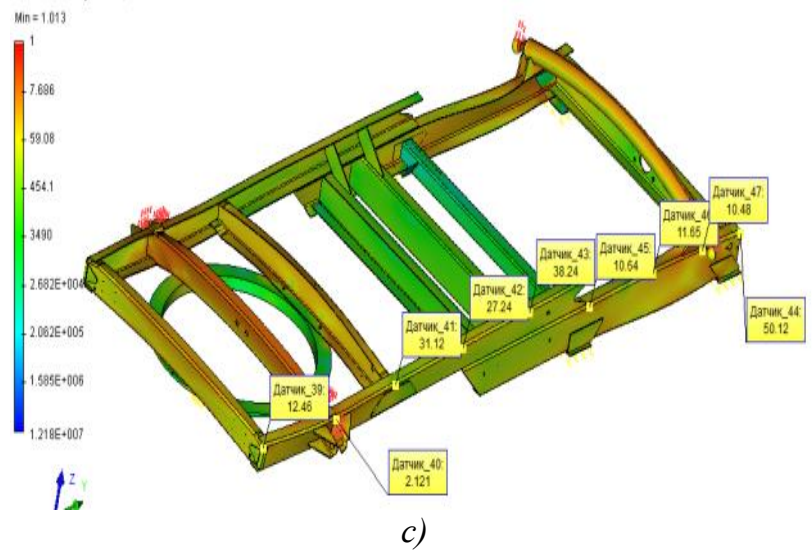

Fig. 2. Equivalent stresses (a), displacements (b), equivalent deformation (c) of frames under load.

The minimum and maximum values of stress, displacement, and equivalent frame deformation are presented in Table 1. 
Table 1. The minimum and maximum values of stress, displacement, and equivalent frame deformation

\begin{tabular}{|c|c|c|c|c|}
\hline Type & Minimum & Space & Maximum & Space \\
\hline Stress & $\begin{array}{l}0.014 \mathrm{MPa} \\
\text { Node: } 40102\end{array}$ & $\begin{array}{l}987.25 \mathrm{~mm} \\
480.258 \mathrm{~mm} \\
1000.32 \mathrm{~mm}\end{array}$ & $\begin{array}{l}104 \mathrm{MPa} \\
\text { Node: } 34306\end{array}$ & $\begin{array}{l}596.28 \mathrm{~mm}, \\
735.104 \mathrm{~mm} \text {, } \\
353.225 \mathrm{~mm} .\end{array}$ \\
\hline Displacement & $\begin{array}{r}0 \mathrm{~m} \\
\text { Node: } 68432\end{array}$ & $\begin{array}{l}1217 \mathrm{~mm}, \\
611.704 \mathrm{~mm}, \\
173.003 \mathrm{~mm}\end{array}$ & $\begin{array}{c}0.00051689 \mathrm{~m} \\
\text { Node: } 62415\end{array}$ & $\begin{array}{l}233.429 \mathrm{~mm} \text {, } \\
402.447 \mathrm{~mm} \text {, } \\
-176.73 \mathrm{~mm} .\end{array}$ \\
\hline $\begin{array}{c}\text { Equivalent of } \\
\text { deformation }\end{array}$ & $\begin{array}{l}1.013 \\
\text { Element: } \\
35402\end{array}$ & $\begin{array}{l}526.367 \mathrm{~mm}, \\
617.894 \mathrm{~mm}, \\
-170.428 \mathrm{~mm} .\end{array}$ & $\begin{array}{c}56.1423 \\
\text { Element: } 6873\end{array}$ & $\begin{array}{c}393.42 \mathrm{~mm}, \\
513.651 \mathrm{~mm} \text {, } \\
-93.6313 \mathrm{~mm} .\end{array}$ \\
\hline
\end{tabular}

Figure 3 shows the graphs of the stress value, displacement, and the equivalent deformation in the frame side member of the universal chassis of the tractor trailer.

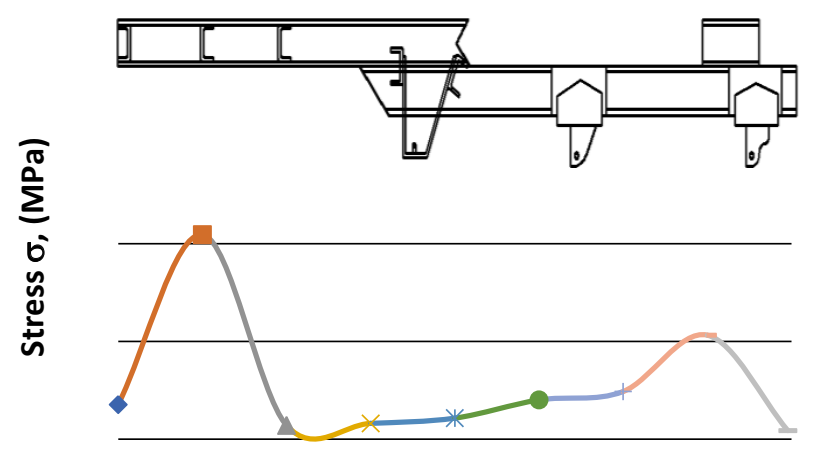

Length, $L$ (m)

a)

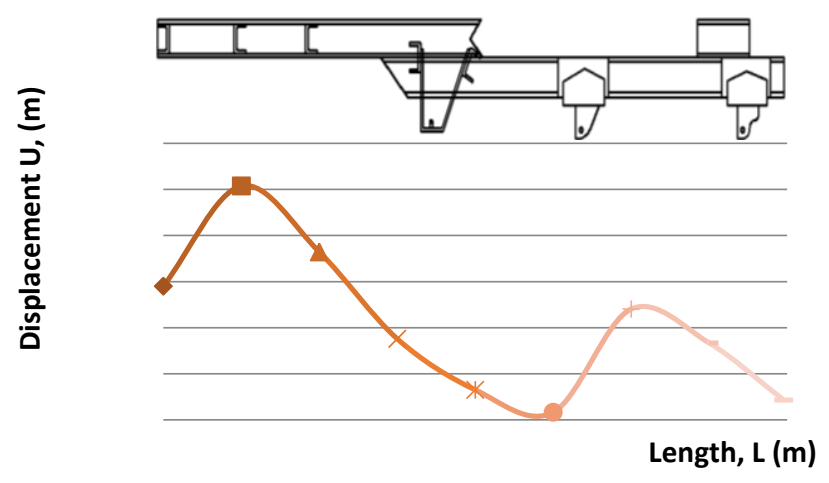

b) 


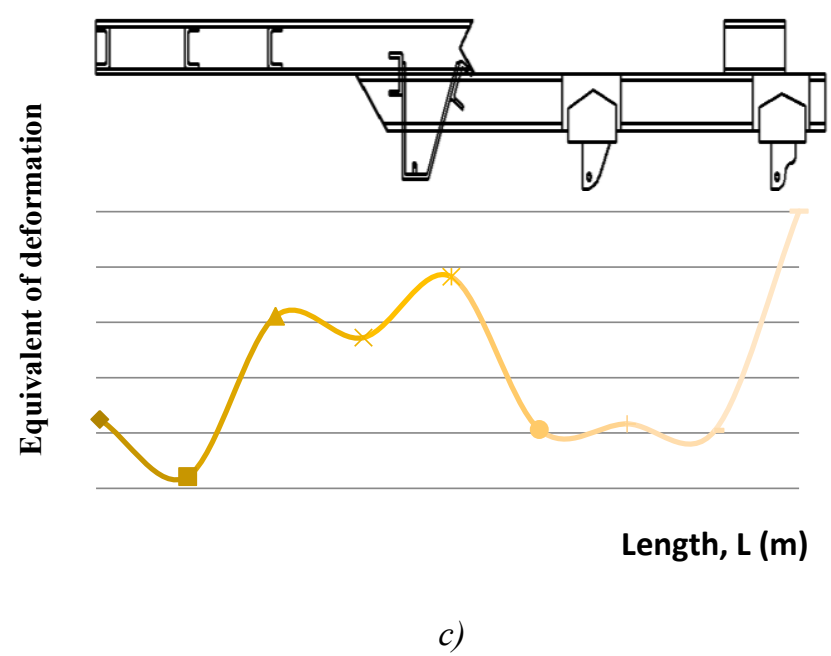

Fig. 3. Graphs of equivalent stress (a), displacement (b), equivalent deformation (c) of frames under load.

The authors of [7] also considered the stress-strain state of the frame. In this case, the finite element was considered in the types of the bar. The forces and moments acting on the bar are shown in figure 4.

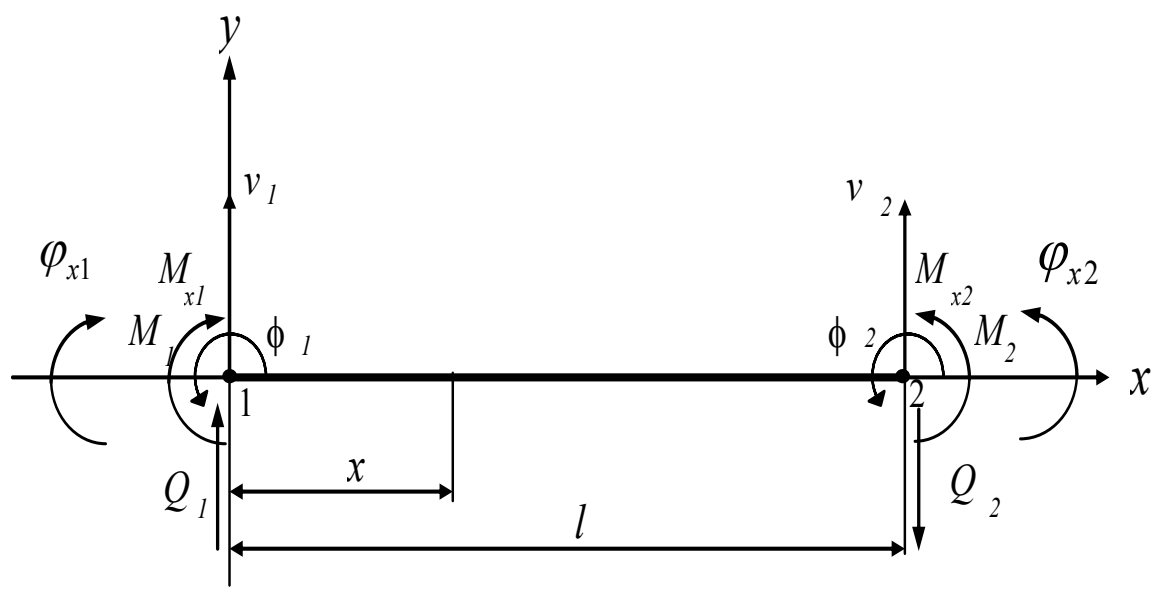

Fig. 4. Diagram of forces and moments acting on a bar element.

The system of general equations of forces and moments acting on the spar (taking into account bending and torsion) is as follows [8]: 


$$
\left[\begin{array}{c}
Q_{1} \\
M_{1} \\
Q_{2} \\
M_{2} \\
M_{x 1} \\
M_{x 2}
\end{array}\right]=\left[\begin{array}{cccccc}
\frac{12 E J}{l^{3}} & \frac{6 E J}{l^{2}} & -\frac{12 E J}{l^{3}} & \frac{6 E J}{l^{2}} & 0 & 0 \\
\frac{6 E J}{l^{2}} & \frac{4 E J}{l} & -\frac{6 E J}{l^{2}} & \frac{2 E J}{l} & 0 & 0 \\
-\frac{12 E J}{l^{3}} & -\frac{6 E J}{l^{2}} & \frac{12 E J}{l^{3}} & -\frac{6 E J}{l^{2}} & 0 & 0 \\
\frac{6 E J}{l^{2}} & \frac{2 E J}{l} & -\frac{6 E J}{l^{2}} & \frac{4 E J}{l} & 0 & 0 \\
0 & 0 & 0 & 0 & \frac{G J_{\mathrm{k}}}{l} & -\frac{G J_{\mathrm{k}}}{l} \\
0 & 0 & 0 & 0 & -\frac{G J_{\mathrm{k}}}{l} & \frac{G J}{l}
\end{array}\right]\left[\begin{array}{c}
v_{1} \\
\varphi_{1} \\
v_{2} \\
\varphi_{2} \\
\phi_{x 1} \\
\phi_{x 2}
\end{array}\right]=[K][u]
$$

Fig. 5. shows the design diagram of the frame structure, taking into account the influence of elastic springs.

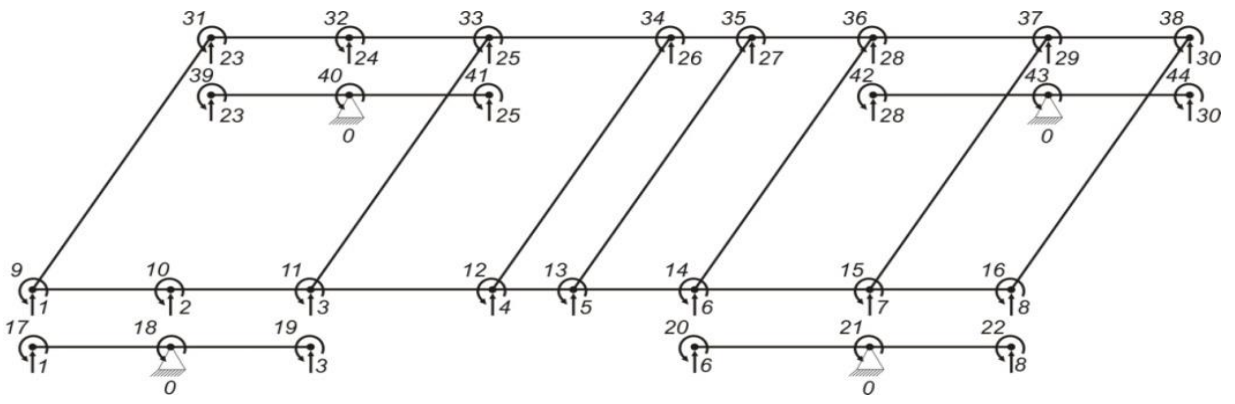

Fig. 5. Calculation scheme

When constructing the design scheme of a thin-walled bar, consider its "middle" surface, which passes through the middle of the elements that form the bar [9]. The trace of the middle surface in the plane of the cross-section forms the profile of the section (figure 5).

According to the profile outline, two types of rods are distinguished:

- rods with a closed profile;

- rods with an open profile.

The system of equations was implemented in the Basic program. Based on the calculations of the frame of a tractor trailer with a carrying capacity of 4 tons, the maximum stress in the spar was determined, which was $106 \mathrm{MPa}$.

The experimental value of the maximum stress in the spar was $102 \mathrm{MPa}$, and the calculated maximum stress according to the T-Flex program was $104 \mathrm{MPa}$ (figure 6).

The relative difference in the values of the maximum stresses in the side member of the tractor trailer frame is less than $4 \%$.

The calculations were made for a static load, considering the safety factor k equal to 1.5 and the dynamic factor $k_{d}$ equal to 1 . 


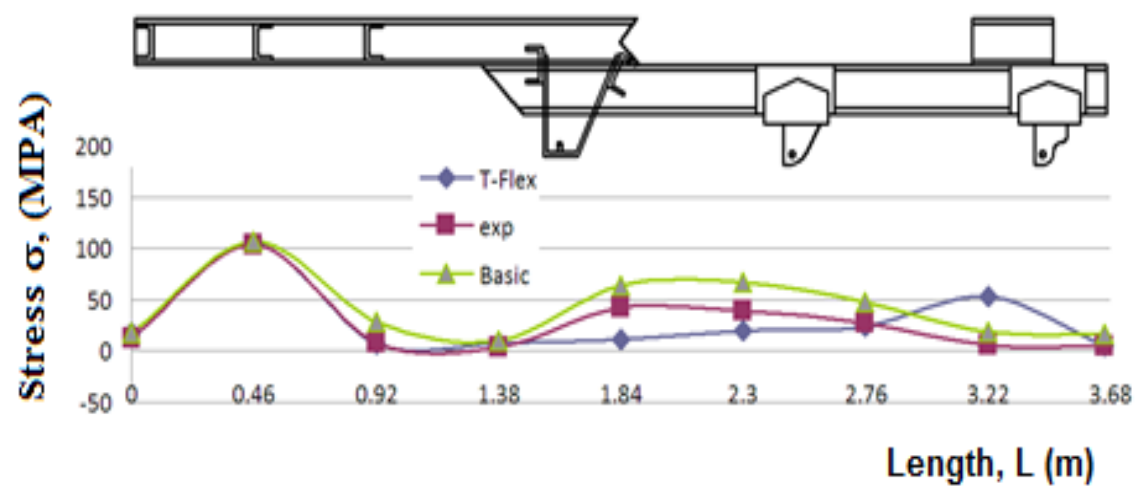

Fig. 6. Comparative graphs of stress changes in the spar obtained using the T-Flex, Basic programs, and experiment.

\section{Conclusions}

Analysis of the graphs shows that the value of the maximum stress obtained using the TFlex program is $104 \mathrm{MPa}$. If we take into account that for a spar with the material - steel 25 and a yield point $\sigma_{\mathrm{T}}=274 \mathrm{MPa}$, the permissible stress when calculating for bending by a static load has a value $[\sigma]=\frac{\sigma_{T}}{k \cdot k_{\mathrm{B}}}=\frac{274}{1,5 \cdot 1}=182.7 \mathrm{MPa}$, where $\boldsymbol{k}$ is the safety factor; $k_{\mathrm{d}}$ is a dynamic coefficient, then for the selected geometrical parameters of the spar of a 4-ton trailer satisfy the strength conditions when driving on an asphalt concrete road.

Using this method, calculations were also carried out for cases where the safety factor is $k=1.5$ and the dynamic factor is $k_{d}=2.5$. The maximum stress value for the T-Flex program was $234 \mathrm{MPa}$, for the Basic program, $237 \mathrm{MPa}$, and the experiment, $256 \mathrm{MPa}$. Comparative analysis shows that the results of the maximum stress in the spar obtained using the T-Flex program correlate well with the experimental data $(8.6 \%)$ and the results obtained using the Basic program (1.3\%). The maximum stress obtained for the adopted safety and dynamic factors satisfies the strength conditions.

Thus, a comparative analysis of the results obtained showed that using the T-FlexCAD software package, it is possible to calculate, with an accuracy of $9 \%$, the characteristics of the static (dynamic) strength of the frame structure of a tractor trailer of a universal chassis.

\section{References}

1. http://ru.annaburger.de/WechselsystemMultiLandPlus.html

2. Archit Tomar1 \& Dheer Singh - "Static Analysis, Modal Analysis and Design Modification in Chassis Frame to Optimize Weight by Using Composite Material" International Journal of Mechanical Engineering (IJME) ISSN(P): 2319-2240 ; ISSN(E): 2319-2259 Vol. 5, Issue 1, pp 101-108. Dec - Jan (2016)

3. Priyanka Ranu, Rajeev Singh Chauhan, Dr. V.N. Bartaria. Mathematical Modelling and Analysis of Automotive Chassis with Composites Materials Using Fem // International Journal for Research in Applied Science \& Engineering Technology (IJRASET). Volume 5 Issue VI, - pp. 153-158. June (2017). ISSN: 2321-9653

4. Divyesh N. Chaudhari, Prof. Vinod M. Makwana, Prof. Dharmeet J. Patel - "A Review Paper on Strength and Rigidity analysis of Heavy Vehicle Chassis for different frame cross section by analytically and FEA under various loading 
condition" International Journal of Advance Research in Engineering, Science \& Technology(IJAREST), ISSN(O):2393-9877, ISSN(P): 2394-2444, Volume 2, Issue 12, Impact Factor: 2.12. December (2015)

5. Mohd Azizi Muhammad Nor., Helmi Rashid., Wan Mohd Faizul Wan Mahyuddin., Mohd Azuan Mohd Azlan., Jamaluddin Mahmud., "Stress Analysis of a Low Loader Chassis" International Symposium on Robotics and Intelligent Sensors 2012 (IRIS 2012).

6. http://www.tflexcad.ru

7. Shermukhamedov A. A., Togaev A.A. Calculating the stress-strain state of frame structures of autotractor trailers at various external influences // European Applied Sciences. - Stuttgart (Germany), - №1. - pp. 70-76. (2016).

8. Zenkevich O.V., Taylor R.L. The Finite Element Method. Fifth edition. Volume 2: Solid Mechanics. Butterworth-Heinemann. Linacre House, Jordan Hill, Oxford OX2 8DP, -P. 479. (2000).

9. Belikov G.V. Fundamentals of calculating the strength reliability of special structural elements of cars and tractors: a tutorial. - Ulyanovsk: U1STU,.- 98 p. (2007)

10. Adilkhodjaev A., Hasanov B., Shaumarov S., Kondrashchenko V. Aerated concrete with predetermined pore parameters for the exterior walls of energy efficient buildings, IOP Conference Series: Materials Science and Engineering, 2021, 1030(1), 012006

11. Khasanov B., Vatin N., Mirzaev T., Suyunov A., Radjabov M. Analysis of the mode of squeezing out excess water for mixing concrete mixture in the process of peristaltic compaction, IOP Conference Series: Materials Science and Engineering, 2021, 1030(1), 012021

12. Rybakov V., Jos V., Raimova I., and Kudryavtsev K. Modal analysis of frameless arches made of thin-walled steel profiles. IOP Conf. Ser. Mater. Sci. Eng. 883, (2020).

13. Khasanov B., Vatin N., Mirzaev T., Suyunov A., Radjabov M. Physicochemical fundamentals of modifying concrete mix and concrete, IOP Conference Series: Materials Science and Engineering, 2021, 1030(1), 012022

14. Khasanov B., Vatin N., Ismailova Z., Mirzaev T. Physical modification of concrete mix and concrete, IOP Conference Series: Materials Science and Engineering, 2020, 883(1), 012205

15. Kattakulov F., Muslimov T., Khusainov A., Vokhidov O., Sultanov S. Water resource saving in irrigation networks through improving the efficiency of reinforced concrete coatings, IOP Conference Series: Materials Science and Engineering, 883(1), 012053, (2020)

16. Khasanov B., Irmuhamedova L., Firlina G., Mirzaev T. Theoretical foundations of the structure formation of cement stone and concrete, IOP Conference Series: Materials Science and Engineering, 2020, 869(3), 032032 